\title{
PRODUÇÃO DE MUDAS DE ALFACE (Lactuta sativa L.) EM SUBSTRATO COMPOSTO POR HÚMUS E RESÍDUOS DO BENEFICIAMENTO DOS GRÃOS DE PIMENTA-DO-REINO
}

\author{
PRODUCTION OF LETTUCE SEEDLINGS (Lactuta sativa L.) IN \\ SUBSTRATE COMPOSED OF HUMUS AND WASTES FROM THE BLACK \\ PEPPER BEAN DRYING PROCESS
}

\author{
${ }^{1}$ Larissa Ionara Silva Paula \\ ${ }^{2}$ Paola Alfonsa Vieira Lo Monaco \\ ${ }^{3}$ Marcelo Rodrigo Krause \\ ${ }^{4}$ Paola Honorato Salla \\ ${ }^{5 *}$ Rodrigo Junior Nandorf \\ ${ }^{6}$ Cassiele Moreira
}

\begin{abstract}
${ }^{1}$ Instituto Federal do Espírito Santo, Campus Santa Teresa. E-mail: larissaionarasilvapaula@gmail.com ${ }^{2}$ Instituto Federal do Espírito Santo, Campus Santa Teresa. E-mail: paolalm@ifes.edu.br ${ }^{3}$ Universidade Federal de Viçosa. E-mail: agro.krause@gmail.com ${ }^{4}$ Instituto Federal do Espírito Santo, Campus Santa Teresa. E-mail: paola.hsalla@gmail.com ${ }^{5}$ Instituto Federal do Espírito Santo, Campus Santa Teresa. E-mail: rodrigojrnandorf@gmail.com ${ }^{6}$ Instituto Federal do Espírito Santo, Campus Santa Teresa. E-mail: cassiele.moreira.cm@gmail.com *Autor de correspondência
\end{abstract}

Artigo submetido em 22/06/2020, aceito em 14/10/2020 e publicado em 28/12/2020.

\begin{abstract}
Resumo: Estudos relacionados ao aproveitamento de resíduos agrícolas na produção de mudas de alface tornaram-se fundamentais por reduzir o custo nesta etapa e por minimizar o risco de contaminação ambiental decorrente do descarte inadequado. Este estudo teve como objetivo avaliar o efeito do aumento dos níveis de resíduos do processamento de grãos de pimenta (moinha de pimenta) e diminuição dos níveis de húmus de minhoca na qualidade de mudas de alface. O experimento foi conduzido em delineamento inteiramente casualizado, com seis tratamentos e dez repetições, sendo: T0: $0 \%$ moinha de pimenta (MP) + 100\% de húmus $(\mathrm{H})$; T1: $10 \% \mathrm{MP}+90 \% \mathrm{H}$; T2: $20 \% \mathrm{MP}+80 \%$ H; T3: $30 \%$ MP + 70\% H; T4: 40\% MP e 60\% H; T5: 50\% de MP e 50\% de H. 40 dias após a semeadura, foram avaliados: altura da planta, diâmetro do caule, peso seco da raiz, peso seco da parte aérea, massa total de matéria seca e Índice de Qualidade Dickson. A associação da moinha de pimenta com o húmus de minhoca promoveu uma melhor qualidade de mudas de alface em comparação com o uso exclusivo de húmus. Recomenda-se o uso de substrato alternativo contendo $20 \%$ de moinha de pimenta e 80\% de húmus na produção de mudas de alface.
\end{abstract}

Palavras-chave: substrato; resíduo; hortaliças; sustentabilidade.

Abstract: Studies concerning the use of agricultural residues in the production of lettuce seedlings have become fundamental for reducing the cost in this stage and for minimizing the risk of environmental contamination due to inappropriate disposal. In this study, we aim to evaluate the effect of increasing levels of wastes from the black pepper bean drying process ("moinha pepper") and decreasing levels of humus on the quality of lettuce seedlings. The experiment was carried out in a 
randomized isolated design (DIC), with six sessions and ten repetitions, being: T0: $0 \%$ moinha pepper (MP) + 100\% humus (H); T1: 10\% MP + 90\% H; T2: 20\% MP + 80\% H; T3: 30\% MP + 70\% H; T4: $40 \% \mathrm{MP}$ and $60 \% \mathrm{H}$; T5: $50 \%$ of the MP and $50 \%$ of the $\mathrm{H}$. At 40 days after the seminar, the following aspects were evaluated: plant height, stem diameter, dry root weight, dry shoot weight, dry shoot weight, total matter mass drought and Dickson's quality index. The association of the moinha pepper with humus promoted a better quality of lettuce seedlings compared to the exclusive use of humus. It is recommended to use the alternative substrate containing $20 \%$ moinha pepperand and $80 \%$ humus in the production of lettuce seedlings.

Keywords: substrate; residue; vegetables; sustainability.

\section{INTRODUÇÃO}

A alface (Lactuca sativa L.) é uma cultura de grande importância socioeconômica, a qual contribui com a geração de emprego e rendas, exercendo também um importante papel social, em razão de contribuir para a fixação do homem no campo (SILVA et al., 2017).

Uma das principais etapas do sistema produtivo da alface é a produção de mudas, pois influencia no desempenho final e nutricional das plantas (FREITAS et al., 2013). Sendo assim, a escolha e o manejo correto do substrato são essenciais para a obtenção de mudas de qualidade (BACKES e KÄMPF,1991).

Os substratos comumente utilizados para a produção de mudas de alface são os comerciais, constituindo-se em um custo a mais na etapa de produção e de formação de mudas.

O uso de resíduos agrícolas na composição de substratos pode ser uma solução para tornar as atividades mais sustentáveis, pois visa a eliminação de um problema ambiental, pelo fato de serem aproveitados e dispostos de forma harmônica no meio ambiente, e, ao mesmo tempo, promove a redução nos custos de produção. Com o intuito de reduzir custos com os substratos comerciais e aproveitar a disponibilidade de resíduos agrícolas gerados em cada região, algumas pesquisas têm sido realizadas com diferentes combinações de substratos comerciais e alternativos em mudas de alface destacando-se os trabalhos de Freitas et al.
(2013), Gonçalves et al. (2014), Simões et al. (2015), Nascimento et al., (2011), dentre outros.

Um dos resíduos gerados em elevada quantidade no estado do Espírito Santo é a "moinha de pimenta", proveniente do processo de beneficiamento da pimenta-do-reino. Este resíduo é composto por restos vegetais tais como folhas, galhos, restos de inflorescências e grãos malformados da própria pimenteira, que, durante a etapa de secagem, sofrem queima e são liberados do secador (GUISOLFI et al., 2020). Em razão de sua elevada disponibilidade, da necessidade de dar um destino adequado para esse resíduo, além de diminuir os custos no processo produtivo, vislumbra-se sua utilização como componente de substrato na produção de mudas alface.

Além da moinha de pimenta, o húmus de minhoca pode ser uma interessante opção como componente de substrato para produção de mudas de alface. De acordo com Costa et al. (2012), o húmus de minhoca tem sido utilizado com sucesso como componente de substratos, promovendo a melhoria na qualidade de mudas de alface. O húmus atua sobre atributos físicos do solo, como aeração, porosidade, densidade e capacidade de retenção de água, e disponibiliza nutrientes sob formas prontamente assimiláveis pelas plantas, além de enzimas, ácidos húmicos e hormônios vegetais (LIM et al., 2015).

Diante da dificuldade de se encontrar um material com todas as 
características desejáveis para compor um substrato para produção de mudas, torna-se necessário a mistura de dois ou mais componentes para se conseguir um substrato próximo ao ideal (ARAÚJO NETO et al., 2009). Nesse sentido, em razão de suas características distintas, acredita-se que o húmus e a moinha de pimenta podem ser dois materiais promissores na composição de um substrato para produção de mudas de alface, tornando-se fundamental obter a proporção ideal de cada um na composição do substrato, para se obter mudas de alface com qualidade.

Objetivou-se com este trabalho, avaliar o efeito de níveis crescentes de moinha de pimenta e decrescentes de húmus de minhoca na qualidade de mudas de alface, além de determinar a proporção que permite o melhor desenvolvimento das mudas.

\section{MATERIAIS E MÉTODOS}

O experimento foi implantado e conduzido no período de maio a junho de 2018, em casa de vegetação do setor de Olericultura do Instituto Federal do Espírito Santo, Campus Santa Teresa, localizado no município de Santa Teresa, Espírito Santo (ES), (1848'19'’S; 4040’32'’O; altitude $130 \mathrm{~m}$ ). O clima, segundo a classificação de Köppen, enquadra-se no tipo Cwa (subtropical de inverno seco), com temperatura média anual de $24,6^{\circ} \mathrm{C}$ e precipitação média anual variando entre 700 e $1200 \mathrm{~mm}$. O viveiro onde foi desenvolvido o trabalho era coberto com tela de polipropileno, o que proporcionava a redução da radiação solar em $50 \%$.

Os resíduos utilizados na composição de substrato para produção de mudas de alface foram o proveniente do beneficiamento dos grãos de pimenta-doreino, também conhecido por "moinha de pimenta, e o húmus de minhoca.
A moinha de pimenta foi cedida por produtores da região de São Mateus-ES e o húmus de minhoca californiana pelo setor de Agroecologia do Ifes/Campus Santa Teresa, sendo preparado com folhas provenientes de podas e esterco bovino. Ambos os resíduos foram utilizados da forma como foram coletados, sem necessidade de peneiramento.

A caracterização química e físicoquímica do húmus de minhoca foi realizada no Laboratório de Solos e Meio Ambiente e a moinha de pimenta no Laboratório de Qualidade de Água e Resíduos Sólidos do Ifes. A análise físicoquímica consistiu na determinação da condutividade elétrica (CE), por meio de um condutivímetro de bancada. Já a análise química consistiu na determinação do $\mathrm{pH}$, por meio de um peagâmetro de bancada, e na quantificação das concentrações de carbono orgânico facilmente oxidável $\left(\mathrm{CO}_{\mathrm{fo}}\right)$, carbono orgânico total $\left(\mathrm{CO}_{\mathrm{T}}\right)$, nitrogênio total $\left(\mathrm{N}_{\mathrm{T}}\right)$, fósforo $(\mathrm{P})$ e potássio $(\mathrm{K})$, seguindo-se metodologia descrita por Matos (2015).

Na Tabela 1 apresentam-se os atributos químicos e físico-químico (CE) da moinha de pimenta e do húmus de minhoca utilizados no experimento.

Tabela 1: Atributos químicos da moinha de pimenta (MP) e do Húmus de minhoca (HM)

\begin{tabular}{|c|c|c|c|c|}
\hline Resíduos & $\mathrm{pH}$ & $\begin{array}{c}\mathrm{CE} \\
\mathrm{dS} \mathrm{m}^{-1}\end{array}$ & $\begin{array}{l}\mathrm{N}_{\mathrm{T}} \quad \mathrm{P}_{\mathrm{T}} \\
\text {-----dag kg } \mathrm{kg}^{-1}\end{array}$ & K \\
\hline MP & 7,5 & 1,92 & $2,46 \quad 0,22$ & 0,33 \\
\hline HM & 6,9 & 2,25 & $0,55 \quad 1,21$ & 0,28 \\
\hline
\end{tabular}

Em que pH: potencial hidrogeniônico, CE: condutividade elétrica, NT: nitrogênio total, PT: fósforo total e K: potássio.

Fonte: o autor

O delineamento experimental adotado foi o inteiramente casualizado, com seis tratamentos e dez repetições, sendo aplicados os seguintes tratamentos: T0: $0 \%$ de moinha de pimenta (MP) + 
100\% de húmus $(\mathrm{H})$; T1: $10 \%$ de $\mathrm{MP}+$ 90\% de H; T2: $20 \%$ de MP + 80\% de H; T3: $30 \%$ de MP+ 70\% de H; T4: $40 \%$ de MP e $60 \%$ de $\mathrm{H}$; T5: $50 \%$ de MP e $50 \%$ de H. A quantidade de resíduos adicionada aos tratamentos foi calculada com base no volume.

As sementes utilizadas foram do grupo solta crespa da cultivar Veneranda, com percentual de germinação de $97 \%$ e pureza $99,6 \%$. O semeio foi realizado em bandejas de isopor de 200 células preenchidas com os respectivos substratos pré-umedecidos.

Utilizou-se o sistema de produção de mudas em bandejas suspensas, alocadas em bancadas de alvenaria, irrigadas manualmente uma vez ao dia. Não foram realizadas aplicações de fertilizantes, produtos fitossanitários ou inseticidas.

Após 20 dias foi realizado o desbaste, deixando uma plântula por célula. 40 dias após o semeio (DAS), foram avaliados: altura de planta (AP), diâmetro do coleto (DC), massa seca da raiz (MSR), massa seca da parte aérea (MSPA) e o Índice de Qualidade de Dickson (IQD).

Para a obtenção da altura da parte aérea foi utilizada régua milimetrada, medindo-se da base do colo até o ápice da planta. O diâmetro do coleto foi obtido por meio de um paquímetro digital com precisão de 0,01 $\mathrm{mm}$. As massas secas da raiz e parte aérea foram obtidas por meio do corte das mudas na base do colo. Para a obtenção da massa seca radicular, as raízes foram cuidadosamente lavadas em água

\section{RESULTADOS E DISCUSSÃO}

Na Figura 1 apresenta-se a Altura de Plantas (a), Diâmetro do Coleto (b), Massa Seca de Raiz (c), Massa Seca de Parte Aérea (d) (e) e o Índice de Qualidade de Dickson (f) em função de níveis crescentes de moinha de pimenta e corrente, sob peneira. Posteriormente, os materiais foram acondicionados em sacos de papel e colocados em estufa com circulação de ar forçado a $65^{\circ} \mathrm{C}$ por 72 horas, quando atingiram massa constante.

Em seguida, foi realizada a pesagem dos materiais em balança eletrônica de precisão de 0,01 g. A análise da condutividade elétrica do substrato foi realizada através de um condutivímetro de bancada. Já o IQD foi determinado em função da massa seca total (MST), altura de planta (AP); do diâmetro do coleto (DC); da massa de matéria seca da parte aérea (MSPA) e sistema radicular (MSSR), por meio da Equação 1, proposta por Dickson et al. (1960).

$$
I Q D=\frac{M S T(g)}{(A P(c m) / D C(m m))+(M S P A(g) / M S S R(g))} \text { Eq. (1) }
$$

As variáveis foram submetidas aos testes de normalidade (Shapiro Wilk) e de homocedasticidade (Barttlet), pressupostos para realização da análise de variância. Em caso de efeito significativo pela análise de variância, adotou-se como procedimento a decomposição dos graus de liberdade dos tratamentos em modelos de regressão pelo método dos polinômios ortogonais. Para todos os procedimentos foi adotado um " $\alpha$ " de até 0,05 , utilizando-se o programa estatístico R Core Team versão 4.0.2 (R Core Team, 2020). Os pontos de máxima foram obtidos por meio da derivada primária da equação.

decrescentes de húmus de minhoca no substrato, em mudas de alface, aos 40 DAS. 
Figura 1: Altura de planta (a), diâmetro do coleto (b), massa seca de raiz (c), massa seca de parte aérea (d), Índice de Qualidade de Dickson (e) em mudas de alface produzidas em substrato com níveis crescentes de moinha de pimenta e decrescentes de húmus de minhoca

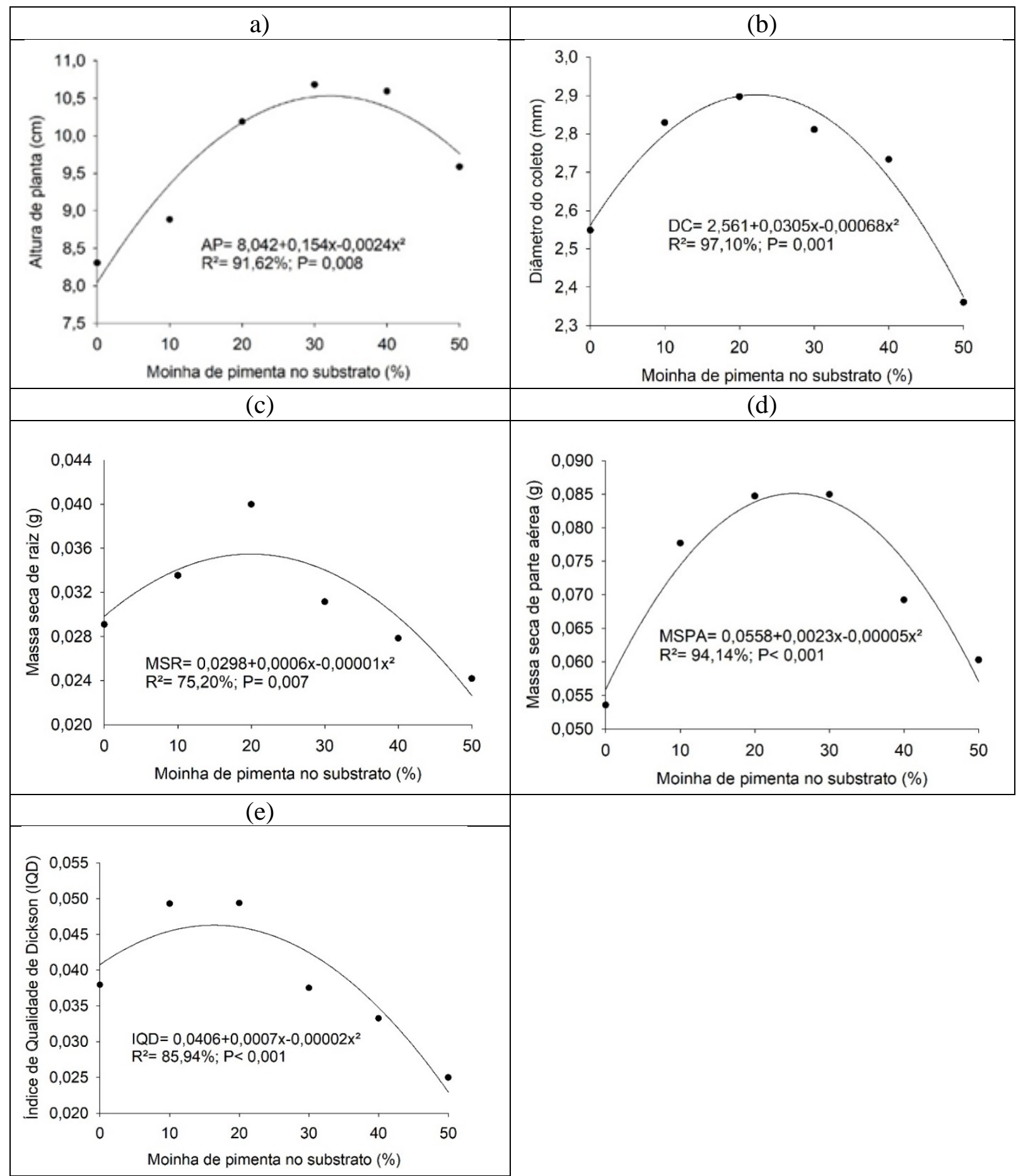

Fonte: autores.

De acordo com a análise de regressão, observa-se que para todas

variáveis analisadas houve um comportamento quadrático $(\mathrm{P}<0,05)$, de tal 
forma que o incremento de moinha no substrato contendo húmus proporcionou valores crescentes das variáveis em torno de 20 a $25 \%$. Acima dessas proporções, os valores das variáveis, no geral, decresceram. Verificou-se também, que os valores máximos obtidos com as referidas proporções foram maiores quando comparados com os valores alcançados pelo uso exclusivo do húmus de minhoca (T0), evidenciando o efeito positivo da moinha de pimenta associada ao húmus de minhoca.

O incremento de moinha de pimenta no substrato proporcionou valores crescentes de altura de planta até a proporção de 32,08\%, obtendo-se o valor máximo de 10,52 cm (Figura 1a). Proporções acima de 32,08\% acarretaram em um decréscimo dessa variável, porém, não inferior ao valor obtido com o uso exclusivo de húmus de minhoca $(8,0 \mathrm{~cm})$. Mesmo com a utilização de proporções maiores de moinha de pimenta na composição do substrato (até 50\%), os valores são ainda superiores quando comparados como maior valor encontrado por Costa et al (2012), que foi 7,47 cm, utilizando substrato composto por húmus + terra preta + fibra de coco.

As plantas com maior diâmetro de colo apresentam maiores tendências à sobrevivência, principalmente pela maior capacidade de formação e de crescimento de novas raízes (TAIZ e ZEIGER, 2013). Além disso, mudas com maiores diâmetros de coleto conferem às plantas maior sustentação e possuem maior resistência ao tombamento.

O substrato contendo $22,42 \%$ de moinha de pimenta e $77,58 \%$ de húmus foi o que apresentou maior diâmetro do coleto (2,9 mm), como pode ser verificado na Figura 1(b). Proporções de moinha de pimenta superiores a 22,42\% acarretaram no decréscimo dessa variável. O maior valor obtido neste trabalho $(2,9 \mathrm{~mm})$ apresenta-se inferior ao obtido por Nascimento et al. (2011), que ao avaliarem substratos de húmus de minhoca a base de diferentes estercos (bovino, ovino e caprino) e cama de frango obtiveram valores de 3,87 mm de diâmetro de coleto, aos 35 DAS. No entanto, ressalta-se que os autores utilizaram a cultivar Lucy Brow, que apresenta algumas variações no tipo morfológico quando comparada a cultivar Veneranda.

Para as variáveis massa seca da raiz (Figura 1c) e massa seca da parte aérea (Figura 1d), o incremento de moinha de pimenta proporcionou valores crescentes dessas variáveis em proporções de até 30 e 23\%, respectivamente. Proporções de moinha de pimenta superiores às mencionadas promoveram a redução das massas secas de raiz e parte aérea da planta.

Os valores máximos obtidos para a MSR (0,0388g) e MSPA $(0,0823 \mathrm{~g})$ podem ser considerados satisfatórios quando comparados com outros autores, combinando diferentes resíduos como componentes de substratos para produção de mudas de alface. Lima et al. (2019), ao utilizarem húmus de minhoca com serragem e casca de arroz para cultivo de alface crespa, obtiveram um valor médio de MSR e MSPA de 0,01 e 0,05 g respectivamente. De forma semelhante, Souza et al. (2020), ao avaliarem materiais orgânicos alternativos para produção de mudas de alface crespa, obtiveram um valor de MSPA de 0,0253 g utilizando apenas o húmus de minhoca. Ao utilizarem o húmus de minhoca associado ao resíduo de cana-de-açúcar, obtiveram valor máximo de 0,0151 g de MSPA, resultado inferior ao obtido neste trabalho. Há de se ponderar que em ambos os trabalhos, as mudas de alface foram avaliadas aos 25 DAS, tempo inferior ao deste trabalho (40 DAS).

É sabido que o húmus associado a outros resíduos apresenta boas condições para desenvolvimento de mudas. Teixeira et al. (2014), ao avaliarem o uso do composto orgânico, húmus de minhoca e 
esterco bovino na produção de mudas de alface, verificaram ótimos resultados nas variáveis de crescimento em mudas de alface. Souza et al. (2020) relacionam este fato às condições físicas e químicas do substrato preparado a partir de húmus de minhoca, com adequado conteúdo de matéria orgânica e boa disponibilidade de nutrientes.

O Índice de Qualidade de Dickson (IQD) destaca-se como um dos índices mais utilizados para avaliar a qualidade de mudas, uma vez que leva em consideração a produção da matéria seca da parte aérea, das raízes e total, a altura e o diâmetro de coleto das plantas (Dickson et al., 1960). De acordo com a Figura (1e), o incremento de moinha de pimenta no substrato proporcionou valores crescentes nos valores de IQD até a proporção de $17,5 \%$, com o valor máximo de 0,0467.

O IQD obtido na associação de húmus de minhoca e moinha de pimenta se sobressai em relação ao IQD encontrado por Simões et al. (2015), que, ao utilizarem casca de arroz carbonizada, fibra de coco, fibra de palmeira e caule decomposto de sumaúma, obtiveram valores de IQD de $0,0013, \quad 0,0012, \quad 0,0015$ e 0,0011 respectivamente, aos 24 DAS. Vale ressaltar que além dos resíduos utilizados foram adicionados calcário e sulfato de potássio em todos os tratamentos.

De modo geral, os resultados obtidos neste trabalho evidenciam o efeito benéfico da moinha de pimenta até uma proporção de aproximadamente $20 \%$ na composição do substrato com húmus de minhoca, já que, para todas as variáveis, o tratamento contendo somente húmus de minhoca apresentou baixos valores. Nesse sentido, o substrato contendo a proporção em torno de $20 \%$ de moinha de pimenta e $80 \%$ de húmus de minhoca torna-se o recomendado. Tal recomendação pode ser justificada pela quantidade adequada de nutrientes prontamente disponíveis pela moinha de pimenta, principalmente o nitrogênio, e pelo conteúdo de matéria orgânica oriundo do húmus de minhoca (Tabela 1), cuja proporção pode ter proporcionado maior estruturação física no substrato, permitindo melhor aeração, drenagem da água e melhor desenvolvimento das raízes. $\mathrm{O}$ adequado conteúdo de fósforo presente no húmus de minhoca (Tabela 1), na referida proporção, também pode ter contribuído para os maiores valores alcançados das variáveis analisadas, em mudas de alface. De acordo com Filgueira (2013), o adequado conteúdo de $\mathrm{P}$ favorece o desenvolvimento do sistema radicular, o vigor das plantas e a produção de matéria seca.

\section{CONCLUSÕES}

A associação da moinha de pimenta com o húmus de minhoca promoveu uma melhor qualidade de mudas em comparação com o uso exclusivo de húmus.

Recomenda-se o uso do substrato alternativo contendo $20 \%$ de moinha de pimenta e $80 \%$ de húmus na produção de mudas de alface.

\section{AGRADECIMENTOS}

Ao Instituto Federal do Espírito Santo, Campus Santa Teresa, e à Pró-Reitoria de Pesquisa e Pós-Graduação do Ifes.

\section{REFERÊNCIAS}

ARAÚJO NETO, S.E.D., AZEVEDO, J.M.A., GALVÃO, R.D.O., OLIVEIRA, E.B.L., FERREIRA, R.L.F. Produção de muda orgânica de pimentão com diferentes substratos. Ciência Rural, v. 39, n. 5, p.1408-1413,2009.

BACKES, M.A.; KÄMPF, A.N. Substrato à base de composto de lixo urbano para a produção de plantas ornamentais. Pesquisa Agropecuária Brasileira, v.26, n.5, p.753-758, 1991. 
COSTA, K.D.S., CARVALHO, I.D.E., FERREIRA, P.V., SILVA, J., TEIXEIRA, J.S. Avaliação de substratos alternativos para a produção de mudas de alface.

Revista Verde de Agroecologia e Desenvolvimento Sustentável, v.7, n.5, p. 58-62. 2012.

DICKSON, A., LEAF, A. L., HOSNER, J. F. Quality appraisal of white spruce and white pine seedling stock in nurseries. The Forestry Chronicle, v. 36, n. 1, p. 10-13, 1960.

FILGUEIRA, F. A. R. Novo manual de olericultura: agrotecnologia moderna na produção e comercialização de

hortaliças. Viçosa, MG: UFV, 421 p.2013.

FREITAS, G.A., SILVA, R.R., BARROS, H.B., MELO, A.V., ABRAHÃO, W.A.P. Produção de mudas de alface em função de diferentes combinações de substratos.

Revista Ciência Agronômica, v.44, n.1, p. 159-166, 2013.

GONÇALVES, M. S., FACCHI, D. P., BRANDÃO, M.I., BAUER, M., PARIS JUNIOR, O. Produção de mudas de alface e couve utilizando composto proveniente de resíduos agroindustriais. Revista

Brasileira de Agroecologia, v. 9, n. 1, p. 216-224. 2014.

GUISOLFI, L.P., LO MONACO, P.A.V., KRAUSE, M.R., MENEGLHELI, C.M., ALMEIDA, K.M., MENEGHELLI, L.A.M, VIEIRA, G.H.S. Agricultural wastes as alternative substrates in the production of conilon coffee seedlings.

Bioscience Journal, v.36, n.3, p.792-798. 2020.

LIM, S.L., WU, T.Y., LIM, P.N., SHAK, K.P.Y. The use of vermicompost in organic farming: overview, effects on soil and economics. Journal of the Science of Food and Agriculture, v.95, n.6, p. 11431156, 2015.
LIMA, M. V. G., DOS SANTOS FILHO, C. A., FERREIRA, J. V. V., DE SOUZA, K. G., SHOCKNESS, L. D. S. F., BENTO, G. F. Vermicompostos como substratos no desempenho de mudas de alface e rúcula. Revista Verde de Agroecologia e Desenvolvimento Sustentável, v. 14, n. 3, p. 374-381, 2019.

MATOS, A. T. Manual de análise de resíduos sólidos e águas residuárias. Viçosa, MG: UFV, 149p. 2015.

NASCIMENTO, J.S.; MOTTA, I.S.; SILVA, F.M.; CARNEIRO, L.F.; ZANCANARO, R.P.P.; FROESS, C.Q. Avaliação de substratos de húmus de minhoca na produção de mudas de alface (Lactuca sativa) cultivar Lucy Brown. Cadernos de Agroecologia, v. 7, n. 2, p.1-5, 2011.

SILVA, A.C., SILVA, V.S.G., MANTOVANELLI, B.C., SANTOS, G.B. Formação de mudas de alface em diferentes bandejas e substratos. Revista da Universidade Vale do Rio Verde, Três Corações, v.15, n.1, p. 465-471, 2017.

SIMÕES A.C., ALVES, G.K.E.B., FERREIRA, R.L.F., ARAUJO NETO, S.E. Qualidade da muda e produtividade de alface orgânica com condicionadores de substrato. Horticultura Brasileira, v.33. n.4, p. 521-526, 2015.

SOUZA, C. J., USHIWATA, S. Y., REIS, R. D. G. E., VILAR, C. C., DE SOUZA, Â. A., DE SOUZA, M. E. Avaliação de materiais orgânicos alternativos para produção de mudas de alface. Global science and technology, v. 13, n. 2, p.186199, 2020.

R Core Team (2020). R: A language and environment for statistical computing. $\mathrm{R}$ Foundation for Statistical Computing, Vienna, Austria. URL https://www.Rproject.org/. 
TAIZ, L., ZEIGER, E. Fisiologia vegetal.

Porto Alegre: Editora Artmed, 918 p. 2013.

TEIXEIRA, A.G., JAEGGI, M.E.P.C., MONTEIRO, E.C., LIMA, W.L.

Substratos orgânicos na produção de mudas de alface. Enciclopedia Biosfera, Centro Científico Conhecer. Goiânia, v.10, n.18, p. 2783, 2014. 